\title{
Traffic-related activities driven dust-bound magnetic pollution in urban road-system: Case study of Xiamen island, China
}

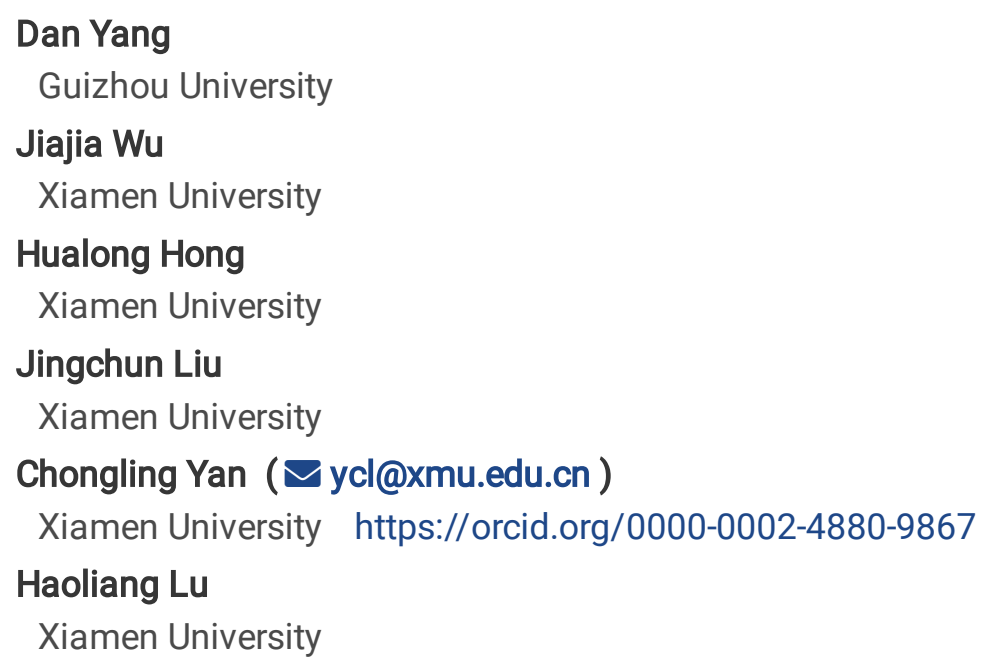

\section{Research Article}

Keywords: Iron-bearing minerals, Magnetic susceptibility, Magnetization, Roadside dust

Posted Date: March 11th, 2021

DOI: https://doi.org/10.21203/rs.3.rs-274340/v1

License: @ (i) This work is licensed under a Creative Commons Attribution 4.0 International License. Read Full License

Version of Record: A version of this preprint was published at Environmental Chemistry Letters on July 22nd, 2021. See the published version at https://doi.org/10.1007/s10311-021-01270-3. 


\section{Abstract}

Sources of magnetic phases in urban dust include traffic-related activities, industrial products and detrital minerals. Exposure to magnetic phases in urban dust co-associated with trace metals is associated with respiratory ailments in sensitive organisms. Here, we collected samples of surface roadside dust and topsoil from Xiamen island, Fujian, China and then magnetic properties were determined using rock-magnetic methods. Magnetic particle concentrations in surface roadside dust was found to be significantly high compared with magnetic content in topsoil using magnetic susceptibility $(\chi \mathrm{LF})$, saturation isothermal remanent magnetization (SIRM) and susceptibility of anhysteretic remanent magnetization ( $\chi$ ARM). Roadside dusts had much lower percent frequency-dependent susceptibility $(1.83 \pm 0.12 \%)$ than topsoil ( $2.96 \pm$ $0.14 \%)$. Given the $\chi$ ARM/SIRM vs $\chi \mathrm{fd} \%$ and first-order reversal curves, most of the magnetic particles in roadside dust were large than in topsoil. Variable temperature dependence of magnetization, isothermal remanent magnetization decomposition spectra and first-order reversal curves suggested the enhancement of dust $\chi$ LF, SIRM and $\chi$ ARM were related to the exogenous pseudo-single-domain magnetite-like materials. This study provides a better understanding of magnetic ageing of dust particles in coastal cities. These results will be useful in optimizing environmental policies aimed at regulating magnetic dust particles pollution in coastal cities.

\section{Introduction}

Iron-containing minerals are widespread in soil, sediment and atmospheric dust in industrial environments (Cao et al., 2015; Szuszkiewicz et al., 2015), urban road-systems (Wang et al., 2019b; Aguilera et al., 2020; O'Shea et al., 2020), and dust-loaded leaves (Reyes et al., 2013; Cao et al., 2015). Iron of iron-containing minerals was substituted by other elements, e.g. $\mathrm{Cu}, \mathrm{Ni}, \mathrm{Cr} \mathrm{Pb}$ or $\mathrm{Zn}$ during the aging of iron oxides (Aguilar Reyes et al., 2013; Jordanova et al., 2014; Švédová et al., 2020) and these iron oxides may include maghemite, magnetite, hematite, goethite and other iron oxides or a-iron. Variation in the abundance of those iron oxides in soil, sediment and atmospheric dusts leads to variation in magnetic signatures.

The magnetic particle sizes of primary magnetic minerals were mainly in the ultra-fine nano-sized superparamagnetic range and single domain grains (Reyes et al., 2011). The next most abundant magnetic minerals, including the products of coal combustion, industrial emission, and chemical formation are characterized by a low value of SIRM/ARM and XLF/ARM (Reyes et al., 2013; Cao et al., 2015; Zhao et al., 2020). Magnetic particles enrichment of trace metals has been found in the magnetic phases of the multi-domain range (Bourliva et al., 2016; Liu et al., 2019). Elevated concentrations of magnetic particles are related to traffic activities and industrial contributions (Aguilera et al., 2020; Zhao et al., 2020). Exposure to magnetic particles co-associated with trace metals could cause severe adverse effects in sensitive organisms.

The occurrence and characteristics of iron-containing minerals and their environmental implication in topsoil, surface dust, and particles suspended in the air have been studied in Chinese cities e.g. Shanghai (Wang et al., 2019a; Wang et al., 2019b), Nanjing (Li et al., 2014; Leng et al., 2018; Wang et al., 2019c), Wuhan (Zhu et al., 2013) and Hokkien triangle, Fujian (Yang et al., 2020). Changes in magnetic concentration parameters, magnetic dependent grain-size and iron-oxide phases depend on pedogenesis and anthropogenic magnetic inputs. Polluted atmospheric particulates have a higher proportion of magnetic phase in the total magnetic mineral assemblage with coarse magnetic size (Zhao et al., 2020). However, to our knowledge, how the magnetic behaviors of surface dust in main roadsides and in topsoil in park lawns respond to variation in anthropogenic activities has not been established for coastal cities. The main goal of this study was to understand the aging of iron-containing minerals in the surface roadside dust and park lawn top-soil at different sample sites.

\section{Materials And Methods}


Xiamen, the special economic zone of southern Fujian, China, is situated in the mid-latitudinal belt between $24^{\circ} 23^{\prime}$ to $24^{\circ} 54^{\prime} \mathrm{N}$ and $117^{\circ} 52^{\prime}$ to $118^{\circ} 26^{\prime} \mathrm{E}$. The average annual precipitation is $1200 \mathrm{~mm}$, which is mainly concentrated in autumn. The average annual temperature is $20.9^{\circ} \mathrm{C}$ and there is no winter season in this coastal area. Total mileage of public roads was $1051.22 \mathrm{~km}$ in 2020 and $2200 \mathrm{~km}$ in 2018. Xiamen Island, the urban center of Xiamen City, has attracted more than

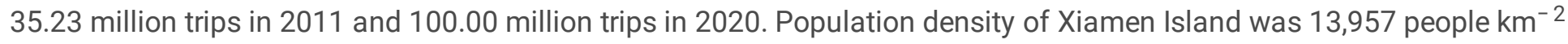
in 2013 and 16,700 people $\mathrm{km}^{-2}$ in 2017. The main sources of particulate matter in Xiamen include vehicle emissions and combustion of biomass, waste and soil (Zhao et al., 2011).

In July 2019, a total of 36 dust samples were collected from the roadside in Xiamen Island (Fig. 1). At each sampling point, four subsamples were obtained using a clean polyethylene brush at a comparable area of $1 \mathrm{~m}^{2}$ and then homogenized in a polyethylene bag. Specifically, the sampling time was selected after the ground had been dry for over 7 days (Wang et al., 2019a). A total of 81 soil samples $(0-20 \mathrm{~cm}$ ) were collected at 21 public gardens in Xiamen Island (Fig. 1). At each sample point, three subsamples were obtained using a stainless-steel trowel.

\subsection{Magnetic measurement}

Mass magnetic susceptibility (XLF, XHF) was measured at two frequencies (470 and $4700 \mathrm{~Hz}$ ) (Dearing, 1999) using a MS2B magnetic susceptibility meter (Bartington Led., UK). Susceptibility of anhysteretic remanent magnetization (XARM) was processed using a DTECH 2000 AF demagnetizer (ASC scientific, USA) at a peak alternating feld of $100 \mathrm{mT}$ and a biasing feld of $0.04 \mathrm{mT}$ (Tan et al., 2018). Saturation isothermal remanent magnetization (SIRM) and IRM- 300 were separately acquired using an ASC Scientific Molspin pulse magnetizer and an AGICO JR6 molspin magnetometer at 1000 $\mathrm{mT}$ and $-300 \mathrm{mT}$. Classical percent frequency-dependent susceptibility (Xfd\%) and $\mathrm{S}_{-300}$ were estimated using Eqs. (1) and (2). respectively. Basic interpretation of magnetic variables in urban dust have been given in (Muñoz et al., 2017) and are not stated in this study.

$$
\chi \mathrm{fd} \%=\frac{\chi \mathrm{LF}-\chi \mathrm{HF}}{\chi \mathrm{LF}} \times 100
$$

1

$$
S_{-300}=\frac{S_{\text {IRM }-I^{-3 R M}-300 \mathrm{mT}}}{2 \times \mathrm{SIRM}}
$$

2

High-temperature thermomagnetic curves were processed using a $34 \mathrm{mT}$ direct current field in a variable field translation balance (Petersen Instrument, Germany). Samples were heated in air to $700 \circ \mathrm{C}$ at a rate of $10 \circ \mathrm{C} \mathrm{min}{ }^{-1}$, and then cooled to room temperature at the same rate. Isothermal remanent magnetization (IRM) curves and first-order reversal curves (FORC) were measured using a MicroMag 3900 vibrating sample magnetometer (Lake Shore Cryotronics, Inc. USA). IRM decomposition spectra were analyzed using the software package IRMUNMIX V2.2 (Heslop et al., 2002) and IRM_CLG1.0 (Kruiver et al., 2001). The first-order reversal curves were performed with the FORCinel software (Harrison and Feinberg, 2008) and the results displayed on a FORC diagram.

For low-temperature measurements, samples were given an IRM in a field of $2.5 \mathrm{~T}$ at $300 \mathrm{~K}$ and cooled to $10 \mathrm{~K}$ in a field of $0 \mathrm{~T}$ in a MPMS-XL7 magnetic property measurement system (Quantum Design, USA) at the State Key Laboratory of Physical Chemistry of Solid Surfaces, Xiamen University. Magnetization was recorded at intervals of $5 \mathrm{~K}$ heated to $300 \mathrm{~K}$ in zero field. The temperature dependence of alternating current magnetization was measured in a peak amplitude of 0.3 $\mathrm{mT}$ at two frequencies ( 1 and $100 \mathrm{~Hz}$ ) within the $10-300 \mathrm{~K}$ temperature range at intervals of $5 \mathrm{~K}$. 
Diffuse reflectance spectra were measured in a Lambda 1050 + UV/Vis/NIR spectrophotometer (PerkinElmer, USA) at Tan Kah Kee innovation laboratory, Xiamen University. The samples were recorded within the 380-710 nm wavelength range at intervals of $2 \mathrm{~nm}$.

\section{Results}

\subsection{Distribution of magnetic particles in topsoil and surface dust}

Magnetic concentration parameters $\chi L F, \chi A R M$, and SIRM were significantly higher in surface roadside dust than in topsoil. $\chi f d$ was significantly lower (40.78\%) in surface roadside dust than in topsoil (Table 1 ). $S_{-300}$, the relative importance of soft coercivity components and hard magnetic fractionations in total magnetic mineral assemblage, did not show any significant difference between surface roadside dust and topsoil. There was no significant difference in magnetic dependent grain-size, XARM/XLF and XARM/SIRM.

Table 1

Statistical summary of magnetic properties

\begin{tabular}{|c|c|c|c|c|c|c|c|}
\hline & $\begin{array}{l}\chi^{\mathrm{LF}} \\
\left(10^{-8}\right. \\
\mathrm{m}^{3} \mathrm{~kg}^{-} \\
\left.{ }^{1}\right)\end{array}$ & $\begin{array}{l}\chi \text { ARM } \\
\left(10^{-8}\right. \\
\mathrm{m}^{3} \mathrm{~kg}^{-} \\
\left.{ }^{1}\right)\end{array}$ & $\begin{array}{l}\text { SIRM } \\
\left(10^{-6}\right. \\
\left.\mathrm{Am}^{2} \mathrm{~kg}^{-1}\right)\end{array}$ & $\begin{array}{l}\chi \mathrm{fd} \% \\
\text { (Dimensionless) }\end{array}$ & $\begin{array}{l}S_{-300} \\
\text { (Dimensionless) }\end{array}$ & $\begin{array}{l}\chi \mathrm{ARM} / \chi \mathrm{LF} \\
\text { (Dimensionless) }\end{array}$ & $\begin{array}{l}\chi \text { ARM/SIRM } \\
\left(10^{-5} \mathrm{~mA}^{-1}\right)\end{array}$ \\
\hline Topsoil & $\begin{array}{l}161.95 \\
\pm \\
11.77 \mathrm{~b}\end{array}$ & $\begin{array}{l}274.83 \\
\pm \\
15.18 \mathrm{~b}\end{array}$ & $\begin{array}{l}11790.15 \\
\pm \\
1150.36 \mathrm{~b}\end{array}$ & $2.96 \pm 0.14 a$ & $98.42 \pm 0.43$ & $1.96 \pm 0.09$ & $16.46 \pm 0.67$ \\
\hline $\begin{array}{l}\text { Surface } \\
\text { dust }\end{array}$ & $\begin{array}{l}249.13 \\
\pm \\
37.96 a\end{array}$ & $\begin{array}{l}374.31 \\
\pm \\
74.56 a\end{array}$ & $\begin{array}{l}26784 \pm \\
3839.99 a\end{array}$ & $1.83 \pm 0.12 b$ & $99.76 \pm 0.19$ & $1.70 \pm 1.99$ & $15.44 \pm 1.35$ \\
\hline
\end{tabular}

\subsection{Variability of magnetic characteristics}

All temperature dependence of magnetization (Fig. 2a1-d1) have a magnetization peak around $510{ }^{\circ} \mathrm{C}$ and then display a major drop around $580^{\circ} \mathrm{C}$. The magnetization in the cooling curves were much higher than in the heating curves between room temperature and $510^{\circ} \mathrm{C}$. The temperature dependence of magnetization of topsoil (e.g. P81, P83) was characterized by a negative magnetization after exposure to $610^{\circ} \mathrm{C}$.

IRM acquisition curves of topsoils (e.g. P81 and P83) were not saturated at $1000 \mathrm{mT}$ (Fig. 2a2-b2) and two coercitivecomponents were identified using the software packages IRMUNMIX V2.2 (Heslop et al., 2002) and IRM_CLG1.0 (Kruiver et al., 2001) (Fig. 2a3-b3, a4-b4). About 47.9 93.0\% of the magnetization was carried by the low coercivity component with median coercive field $\left(B_{1 / 2}\right)$ of 47.9 to $67.6 \mathrm{mT}$. A mineralogical phase with high coercivity component is characterized by the $B_{1 / 2}$ of about 104.7 to $638.7 \mathrm{mT}$ and dispersion parameter (DP) of 0.12 to 0.43 . All dust samples reach over $95 \%$ of saturation isothermal remanent magnetization by $0.3 \mathrm{~T}$ (Fig. 2c2-d2) and all coercivity components were likely subjected to the low coercivity family (Fig. 2c3-d3, c4-d4). In the low-temperature measurements, a continuous decay of magnetization was observed warming up to $300 \mathrm{~K}$ and no obvious magnetization change was identified around $120 \mathrm{~K}$ (Fig. 2a5-d5). Temperature dependence of in-phase magnetization depend on both temperature and frequency (Fig. 3a-d). Coherently, all FORC diagrams have a central peak around the origin of the coercivity axis (Fig. 4a-d) and the divergence of the contour along the magnetic interaction field was 25 to $45 \mathrm{mT}$.

\section{Discussion}




\subsection{Magnetic phases of the complex magnetic mixtures}

Previous investigations suggested values of SIRM/ XLF were $1.13 \times 10^{4} \mathrm{~A} \mathrm{~m}^{-1}$ for magnetite, $2.09 \times 10^{5} \mathrm{~A} \mathrm{~m}^{-1}$ for pyrrhotite, and $2.61 \times 10^{5} \mathrm{~A} \mathrm{~m}^{-1}$ for hematite (Wang et al., 2019c). Here, SIRM/XLF of top-soils and roadside dusts was $12.25 \pm 3.91$ $\times 10^{5} \mathrm{~A} \mathrm{~m}^{-1}$ and $11.19 \pm 2.13 \times 10^{5} \mathrm{~A} \mathrm{~m}^{-1}$, respectively. The $\mathrm{B}_{1 / 2}$ of 47.9 to $67.6 \mathrm{mT}$ and the DP of 0.41 to 0.42 in the IRM decomposition spectra (Fig. 2a3-d4) with significant magnetization loss around $580^{\circ} \mathrm{C}$ (Fig. 2a1-d1) suggested magnetic signing of the magnetite-like phase. During the aging of iron oxides, the magnetic signs of high-coercivity iron-oxides were overshadowed by low-coercivity components, especially the sample of low XLF (Yang et al., 2020). The presence of a highcoercivity hematite in the studied topsoils and roadside dusts was identified by the peak around $565 \mathrm{~nm}$ in the diffuse reflectance spectra (Fig. 3e-h) and a continuous magnetization loss above $610 \circ \mathrm{C}$ in the temperature dependence of magnetization (Fig. 2a1-d1). The peaks around $435 \mathrm{~nm}$ in the diffuse reflectance spectra (Fig. 2e-h), the possibility of goethite cannot rule out. According to (Wang et al., 2019b), the irreversible heating curves and cooling curves are linked to the alteration of ferrimagnetic minerals warming up to $680^{\circ} \mathrm{C}$. Here, magnetization in the cooling curve is higher than those in the heating curve at room temperature (Fig. 2a1-d1) and reflect the thermal alteration of clay and organic matter during the heating processes. A minor magnetization loss near $300-450^{\circ} \mathrm{C}$ during the heating (Fig. 2a1-d1) and the presence of unstable maghemite (Wang et al., 2019b) was also identified.

\subsection{The enhanced magnetic particles in surface roadside dust}

Variations in $\chi$ LF, SIRM and $\chi$ ARM match with the proportion of ferrimagnetic phases, e.g. magnetite, maghemite and pyrrhotine in the total magnetic mineral assemblage. High values of $\chi$ LF and SIRM were related to the abundance of superparamagnetic (SP) and/or multi-domain magnetic phases. As observed in studies of mineralogical dust, the elevated dust $\chi$ LF, SIRM and $\chi$ ARM were associated with anthropogenic magnetic minerals, e.g. industrial activities and trafficrelated sources (Cabanova et al., 2019). Aguilera et al. (2020) found that vehicle exhaust was the dominant magnetic source of street dusts in urban areas. The values of $\chi$ LF varies among different types of dusts: $4603.73 \times 10^{-8} \mathrm{~m}^{3} \mathrm{~kg}^{-1}$ for industrial dusts (Szuszkiewicz et al., 2015), $1100 \pm 320 \times 10^{-8} \mathrm{~m}^{3} \mathrm{~kg}^{-1}$ for subway dusts (Zhang et al., 2011), and $35.6 \pm$ $2.2 \times 10^{5} 10^{-8} \mathrm{~m}^{3} \mathrm{~kg}^{-1}$ for top-soils (Zhang et al., 2012). Here, the values of $\chi$ LF, SIRM and $\chi$ ARM in the roadside dust were much higher than those in the topsoil (Table 1). Similar magnetic signatures of street dust and topsoil have been recorded in Beijing, China (Zhang and Zhang, 2008), Ostrava, Czechia (Švédová et al., 2020) and West Bengal, India (Maity et al., 2020) and reflect the anthropogenic contribution of magnetic phases in the iron-containing minerals. A positive correlation with $\chi \mathrm{LF}$ and SIRM (Fig. $3 \mathrm{~m}$ ) were linked to the ferrimagnets in the magnetic mineral assemblage. By combining temperature dependence of magnetization, isothermal remanent magnetization decomposition spectra and first-order reversal curves, the magnetic phases of roadside dust were revealed to be mainly composed of oxidized magnetite of different magnetic grain size (Fig. 2). Little contribution of paramagnetic minerals was recorded in roadside dust as in-phase magnetization decreased upon cooling from 300 to $10 \mathrm{~K}$ (Fig. 3c-d). The presence of minor SP magnetic phases was evident as the dependence of in-phase magnetization on frequency and temperature (Fig. 3c-d). Atmospheric particulates in pollution (Liu et al., 2019; Wang et al., 2019c), road-deposited sediments (Aguilera et al., 2020; Maity et al., 2020), street dusts (Wang et al., 2011; Wang, 2013; Zhu et al., 2013; Li et al., 2014; Wang et al., 2019b) and dust-loaded leaves (Cao et al., 2015) of low $\chi \mathrm{fd} \%$ have been recorded in other metropolitan sites. Here, $\chi \mathrm{fd} \%$ was significantly lower in surface roadside dust than in park lawn top-soil and suggested the main contributions of the magnetic component of surface roadside dust were exogenous magnetic phases. Consistent with this, a weak relationship between $\chi$ LF with $\chi \mathrm{fd} \%(r=0.05, \mathrm{P}>0.50)$ reflected a negligible contribution of fine pedogenic grains to the elevated $\chi$ LF. Across the studied area, all samples fall in the pseudo-single domain (PSD) range (Fig. 4) with magnetic grains of $\sim 1-5 \mu \mathrm{m}$ (Fig. 3o). Such characteristics have been documented in Loudi (Zhang et al., 2012) and Beijing (Zhang and Zhang, 2008), China, which further suggests that enhanced $\chi$ LF, SIRM and $\chi$ ARM in roadside dust were linked to the local exogenous PSD magnetite- 


\subsection{Environmental implications}

In general, the coexistence of magnetic particles and heavy metals have been documented in atmospheric particulates, road-deposited sediments and urban street dusts (Aguilar Reyes et al., 2013; Leng et al., 2018; Aguilera et al., 2020). The hazard index of magnetic particles in pollution combined with iron and other heavy metals in Thessaloniki, Greece (Bourliva et al., 2016) and Yunnan, China (Tan et al., 2018) were either higher than or very close to the safe level. Evidently, Magnetic minerals in polluted dust enriched with heavy metals have been identified in Thessaloniki, Greece (Bourliva et al., 2016), Warsaw, Poland (Dytłow et al., 2019), Morelia, Mexico (Aguilar Reyes et al., 2013) and Ostrava, Czechia (O'Shea et al., 2020) using SEM-EDS. A significant amount of iron oxides with variable surface charge and high redox activity have been traced in the human brain (Dlháň et al., 2019). The elevated $\chi$ LF, SIRM and $\chi$ ARM in dust (Table 1) were related to the exogenous magnetic minerals and possibly to traffic-related activities. Abundance of magnetic minerals in dust were related to traffic flow, as evidenced by the strong correlation between traffic flow and the magnetic signals of deposited particulate matter (Muñoz et al., 2017). Magnetic particles in polluted dust including atmospheric particulate matter (Qiao et al., 2013; Warrier et al., 2014) and road dusts (Zhang and Zhang, 2008; Wang et al., 2019b), tend to be concentrated in the magnetic size of $\sim 1-5 \mu \mathrm{m}$. Prolonged exposure to those magnetic particles could enhance the occurrence of respiratory ailments in sensitive organisms. Further work is needed to quantitate the occurrence of iron-bearing particles in polluted dust with elemental compositions between magnetic signatures and road type, traffic flow and population size in Xiamen Island.

\section{Conclusions}

Dust $\chi \mathrm{fd} \%$ was found between 0.57 and $4.10 \%$ and reflected a less-important contribution of lithogenic components in the total magnetic mineral assemblage. Analyses of temperature dependence of magnetization, isothermal remanent magnetization, and FORC suggested the elevated dust $\chi$ LF, SIRM and $\chi$ ARM were related to exogenous iron-containing magnetic particles. The type of magnetic minerals both in the topsoil and roadside dust is mainly magnetite-like minerals, with a minor amount of hematite. Consistent with the magnetic size range of $\sim 1-5 \mu \mathrm{m}$ in polluted dust from the coastal cities in Shanghai, China, prolonged exposure to these dusts could exacerbate respiratory ailments in the most sensitive organisms. These data will be useful to optimize environmental policies of air quality in the Xiamen Island, China.

\section{Declarations}

\section{Acknowledgements}

This study was funded by financially supported by National Key R\&D Program of China (2018YFC1406603) and Major Program of National Natural Science Foundation of China (31870483 and 31530008 ). The manuscript was greatly improved by Dr. Adam Roddy at Yale University. Dan Y is grateful to Dr. Weiguo Zhang at State Key Laboratory of Estuarine and Coastal Research, East China Normal University for his help in the magnetic measurements.

\section{Conflict of interest}

The authors declare no conflicts of interest.

\section{References}

Aguilar Reyes, B., Bautista, F., Goguitchaichvili, A., Morales Contreras, J.J., Battu, J., Quintana Owen, P., Carvallo, C., 2013. Rock-magnetic properties of topsoils and urban dust from Morelia (>800,000 inhabitants), Mexico: Implications for anthropogenic pollution monitoring in Mexico's medium size cities. Geofís Int 52, 121-133.

Loading [MathJax]/jax/output/CommonHTML/jax.js 
Aguilera, A., Morales, J.J., Goguitchaichvili, A., García-Oliva, F., Armendariz-Arnez, C., Quintana, P., Bautista, F., 2020. Spatial distribution of magnetic material in urban road dust classified by land use and type of road in San Luis Potosí, Mexico. Air Qual Atmos Health 13, 951-963.

Bourliva, A., Papadopoulou, L., Aidona, E., 2016. Study of road dust magnetic phases as the main carrier of potentially harmful trace elements. Sci Total Environ 553, 380-391.

Cabanova, K., Hrabovska, K., Matejkova, P., Dedkova, K., Tomasek, V., Dvorackova, J., Kukutschova, J., 2019. Settled ironbased road dust and its characteristics and possible association with detection in human tissues. Environ Sci Pollut R 26, 2950-2959.

Cao, L., Appel, E., Hu, S., Yin, G., Lin, H., Rösler, W., 2015. Magnetic response to air pollution recorded by soil and dustloaded leaves in a changing industrial environment. Atmos Environ 119, 304-313.

Dearing, J., 1999. Environmental magnetic sussecptibility: using the Bartington MS2 system. Chi Publishing, England.

Dlháň, L'., Kopáni, M., Boča, R., 2019. Magnetic properties of iron oxides present in the human brain. Polyhedron 157, 505510.

Dytłow, S., Winkler, A., Górka-Kostrubiec, B., Sagnotti, L., 2019. Magnetic, geochemical and granulometric properties of street dust from Warsaw (Poland). J Appl Geophys 169, 58-73.

Harrison, R.J., Feinberg, J.M., 2008. FORCinel: An improved algorithm for calculating first-order reversal curve distributions using locally weighted regression smoothing. Geochemistry Geophysics Geosystems 9, 11.

Heslop, D., Dekkers, M.J., Kruiver, P.P., Oorschot, I.H.M.v., 2002. Analysis of isothermal remanent magnetization acquisition curves using the expectation-maximization algorithm. Geophys J Int 148, 58-64.

Jordanova, D., Jordanova, N., Petrov, P., 2014. Magnetic susceptibility of road deposited sediments at a national scale-relation to population size and urban pollution. Environ Pollut 189, 239-251.

Kruiver, P.P., Dekkers, M.J., Heslop, D., 2001. Quantification of magnetic coercivity components by the analysis of acquisition curves of isothermal remanent magnetisation. Earth Planet Sci Lett 189, 269-276.

Leng, X., Qian, X., Yang, M., Wang, C., Li, H., Wang, J., 2018. Leaf magnetic properties as a method for predicting heavy metal concentrations in PM2.5 using support vector machine: A case study in Nanjing, China. Environ Pollut 242, $922-930$.

Li, H., Qian, X., Wei, H., Zhang, R., Yang, Y., Liu, Z., Hu, W., Gao, H., Wang, Y., 2014. Magnetic properties as proxies for the evaluation of heavy metal contamination in urban street dusts of Nanjing, Southeast China. Geophy J Int 199, $1354-1366$.

Liu, H., Yan, Y., Chang, H., Chen, H., Liang, L., Liu, X., Qiang, X., Sun, Y., 2019. Magnetic signatures of natural and anthropogenic sources of urban dust aerosol. Atmos Chem Phys 19, 731-745.

Maity, R., Venkateshwarlu, M., Mondal, S., Kapawar, M.R., Gain, D., Paul, P., 2020. Magnetic and microscopic characterization of anthropogenically produced magnetic particles: a proxy for environmental pollution. Int J Environ Sci Te, https://doi.org/10.1007/s13762-13020-02902-x.

Muñoz, D., Aguilar, B., Fuentealba, R., Préndez, M., 2017. Environmental studies in two communes of Santiago de Chile by the analysis of magnetic properties of particulate matter deposited on leaves of roadside trees. Atmos Environ 152, 617627.

Loading [MathJax]/jax/output/CommonHTML/jax.js 
O'Shea, M.J., Vann, D.R., Hwang, W., Gieré, R., 2020. A mineralogical and chemical investigation of road dust in Philadelphia, PA, USA. Environ Sci Pollut R 27, 14883-14902.

Qiao, Q., Huang, B., Zhang, C., Piper, J.D.A., Pan, Y., Sun, Y., 2013. Assessment of heavy metal contamination of dustfall in northern China from integrated chemical and magnetic investigation. Atmos Environ 74, 182-193.

Reyes, B.A., Bautista, F., Goguitchaichvili, A., Morton, O., 2011. Magnetic monitoring of top soils of Merida (Southern Mexico). Stud Geophys Geod 55, 377-388.

Reyes, B.A., Mejía, V., Goguitchaichvili, A., Escobar, J., Bayona, G., Bautista, F., Morales, J.C., Ihl, T.J., 2013. Reconnaissance environmental magnetic study of urban soils, dust and leaves from Bogotá, Colombia. Stud Geophys Geod 57, 741-754.

Švédová, B., Matýsek, D., Raclavsk, H., Kucbel, M., Kantor, P., Šafář, M., Raclavský, K., 2020. Variation of the chemical composition of street dust in a highly industrialized city in the interval of ten years. J Environ Manage 267, 110506.

Szuszkiewicz, M., Magiera, T., Kapička, A., Petrovský, E., Grison, H., Gołuchowska, B., 2015. Magnetic characteristics of industrial dust from different sources of emission: A case study of Poland. J Appl Geophys 116, 84-92.

Tan, Z., Lu, S., Zhao, H., Kai, X., Jiaxian, P., Win, M.S., Yu, S., Yonemochi, S., Wang, Q., 2018. Magnetic, geochemical characterization and health risk assessment of road dust in Xuanwei and Fuyuan, China. Environ Geochem Health 40, 1541-1555.

Wang, G., Chen, J., Zhang, W., Chen, Y., Ren, F., Fang, A., Ma, L., 2019a. Relationship between magnetic properties and heavy metal contamination of street dust samples from Shanghai, China. Environ Sci Pollut R 26, 8958-8970.

Wang, G., Chen, J., Zhang, W., Ren, F., Chen, Y., Fang, A., Ma, L., 2019b. Magnetic properties of street dust in Shanghai, China and its relationship to anthropogenic activities. Environ Pollut 255, 113214.

Wang, G., Oldfield, F., Xia, D., Chen, F., Liu, X., Zhang, W., 2011. Magnetic properties and correlation with heavy metals in urban street dust: A case study from the city of Lanzhou, China. Atmos Environ 46, 289-298.

Wang, L., Hu, S., Ma, M., Zhang, Y., Wang, X., Wang, Q., Zhang, Z., Cui, B., Liu, X., 2019c. Magnetic characteristics of atmospheric dustfall in a subtropical monsoon climate zone of China and its environmental implications: A case study of Nanjing. Atmos Environ 212, 231-238.

Wang, X.S., 2013. Mineralogical and chemical composition of magnetic fly ash fraction. Environ Earth Sci 71, $1673-1681$.

Warrier, A.K., Shankar, R., Manjunatha, B.R., Harshavardhana, B.G., 2014. Mineral magnetism of atmospheric dust over southwest coast of India: Impact of anthropogenic activities and implications to public health. J Appl Geophys 102, 1-9.

Yang, D., Wang, M., Liu, J., Deng, T., Yan, C., Ding, Z., Lu, H., 2020. Occurrence and characteristics of iron-bearing minerals in surface road dusts: a case study in the coastal areas of southern Fujian, China. J Soil Sediment 20, 3406-3416.

Zhang, C., Qiao, Q., Appel, E., Huang, B., 2012. Discriminating sources of anthropogenic heavy metals in urban street dusts using magnetic and chemical methods. J Geochem Explor 119-120, 60-75.

Zhang, W., Jiang, H., Dong, C., Yan, Q., Yu, L., Yu, Y., 2011. Magnetic and geochemical characterization of iron pollution in subway dusts in Shanghai, China. Geochem Geophy Geosy 12, Q06Z25.

Zhang, Y., Zhang, S., 2008. Magnetic properties of street dust and topsoil in Beijing and its environmental implications. Chinese Sci Bull 53, 408-417.

Loading [MathJax]/jax/output/CommonHTML/jax.js 
Zhao, G., Zhang, R., Han, Y., Lu, B., Meng, Y., Wang, S., Wang, N., 2020. Identifying environmental pollution recorded in street dust using the magnetic method: a case study from central eastern China. Environ Sci Pollut R, https://doi.org/10.1007/s11356-11020-09771-11354.

Zhao, J., Zhang, F., Xu, Y., Chen, J., Yin, L., Shang, X., Xu, L., 2011. Chemical Characteristics of Particulate Matter during a Heavy Dust Episode in a Coastal City, Xiamen, 2010. Pol J Environ Stud 11, 300-309.

Zhu, Z., Sun, G., Bi, X., Li, Z., Yu, G., 2013. Identification of trace metal pollution in urban dust from kindergartens using magnetic, geochemical and lead isotopic analyses. Atmos Environ 77, 9-15.

\section{Table}

Table 1 Statistical summary of magnetic properties $\quad \chi$ LF (10-8 m3kg-1) $\chi$ ARM (10-8 m3kg-1) SIRM (10-6 Am2kg-1) $\chi \mathrm{fd} \%$ (Dimensionless) S-300 (Dimensionless) $\chi$ ARM $/ \chi$ LF (Dimensionless) $\chi$ ARM/SIRM (10-5 mA- 1 ) Topsoil 161.95 $\pm 11.77 \mathrm{~b} 274.83 \pm 15.18 \mathrm{~b} 11790.15 \pm 1150.36 \mathrm{~b} 2.96 \pm 0.14 \mathrm{a} 98.42 \pm 0.431 .96 \pm 0.0916 .46 \pm 0.67$ Surface dust $249.13 \pm 37.96 a \quad 374.31 \pm 74.56 a \quad 26784 \pm 3839.99 a \quad 1.83 \pm 0.12 b \quad 99.76 \pm 0.191 .70 \pm 1.9915 .44 \pm 1.35$

\section{Figures}

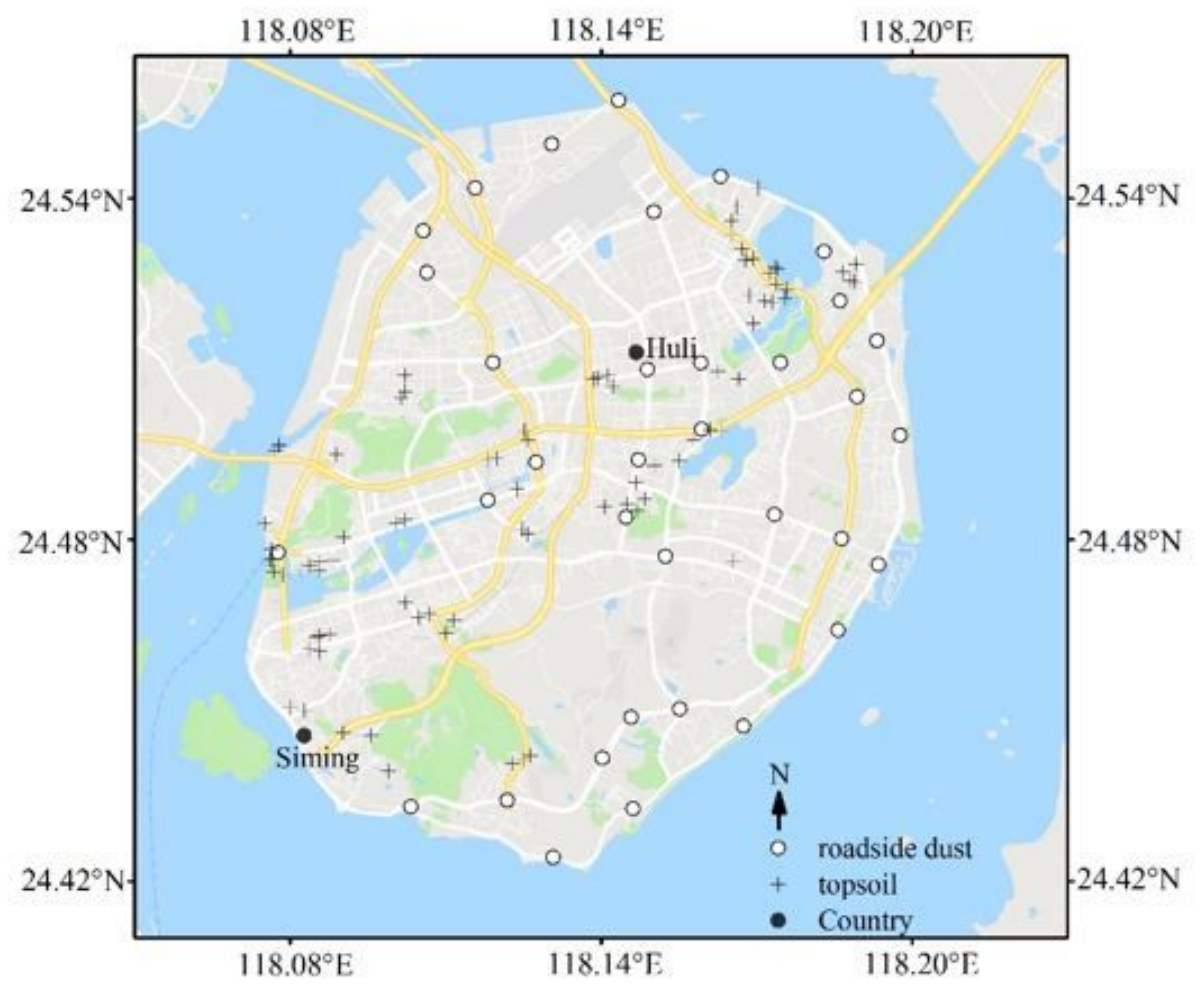

\section{Figure 1}

Map of sampling locations of roadside dust and topsoil in Xiamen Island, China. Note: The designations employed and the presentation of the material on this map do not imply the expression of any opinion whatsoever on the part of Research Square concerning the legal status of any country, territory, city or area or of its authorities, or concerning the delimitation of its frontiers or boundaries. This map has been provided by the authors. 


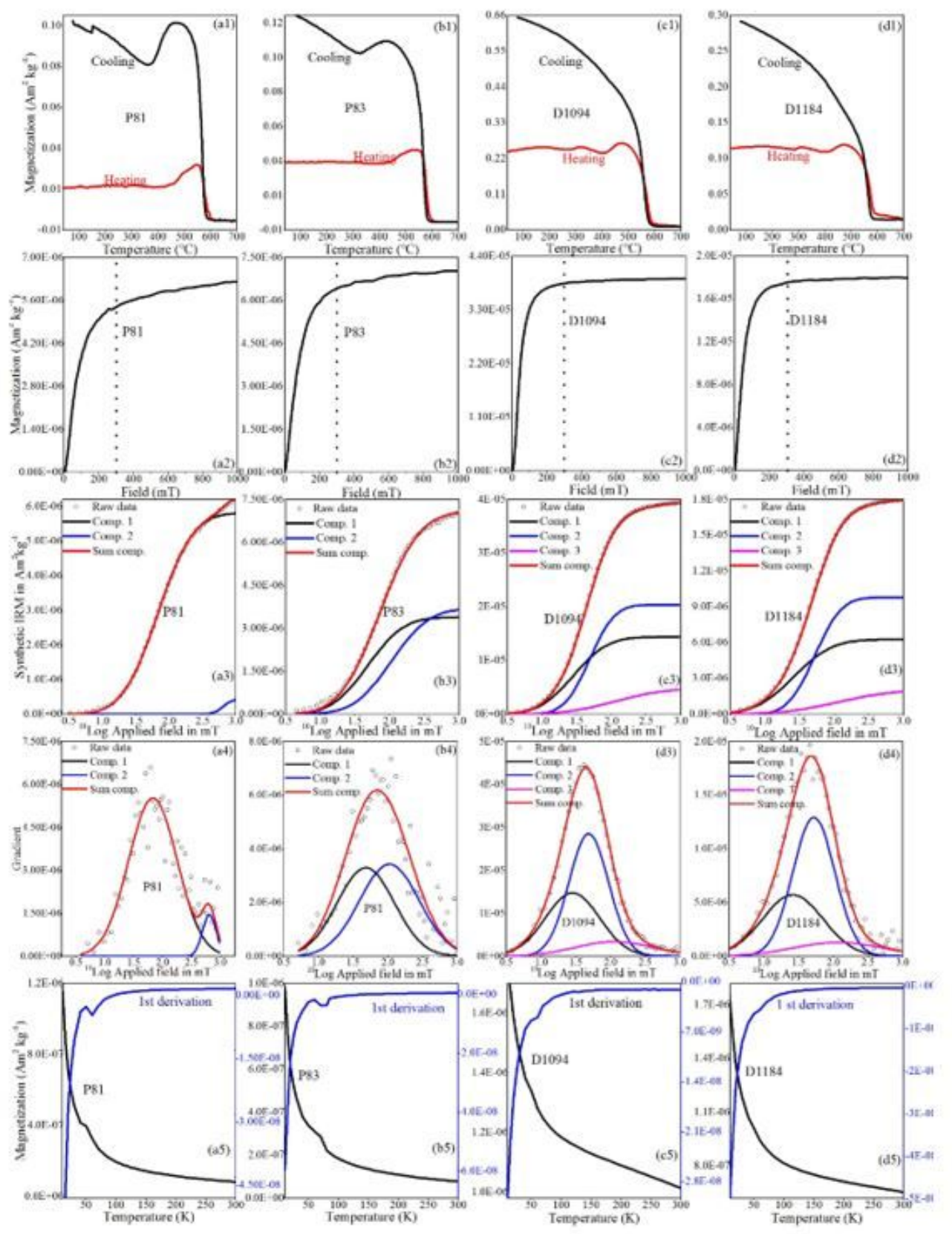

Figure 2

Magnetization as a function of temperature range between room temperature and $700{ }^{\circ} \mathrm{C}$ (a1-d1), field-dependent of magnetization (a2-d2), isothermal remanent magnetization acquisition curves plotted as gradient acquisition plots (a3-d3) and standardized acquisition plots (a4-d4), and low-temperature warming of saturation isothermal remanent magnetization curves (a5-d5) 

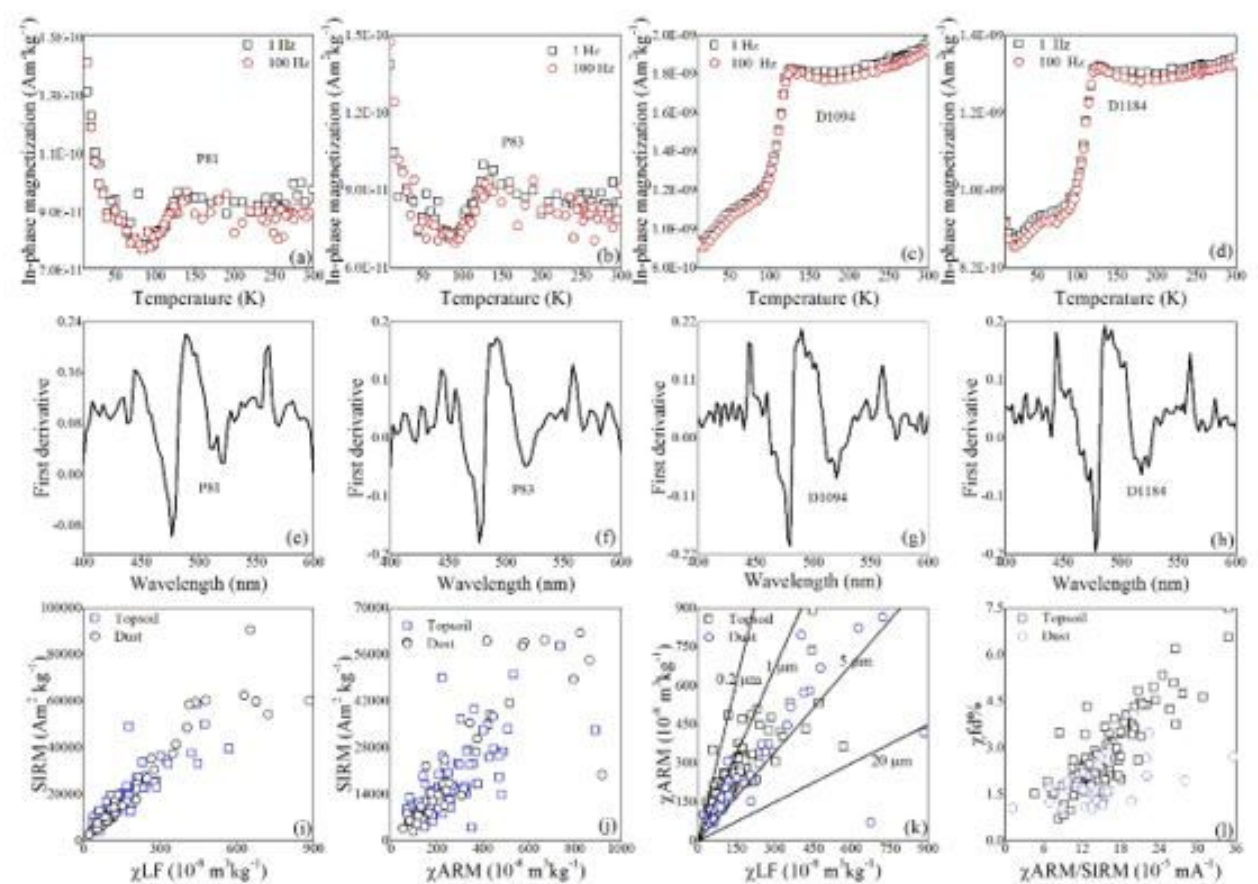

Figure 3

Temperature and frequency dependence of in-phase magnetization (a-d), first derivative spectral curves of diffuse reflectance spectroscopy (e-h), $\chi$ LF vs SIRM (i), $\chi$ ARM vs SIRM (j), $\chi$ LF vs $\chi$ ARM (k), and $\chi$ ARM/SIRM vs $\chi$ fd\% (I)
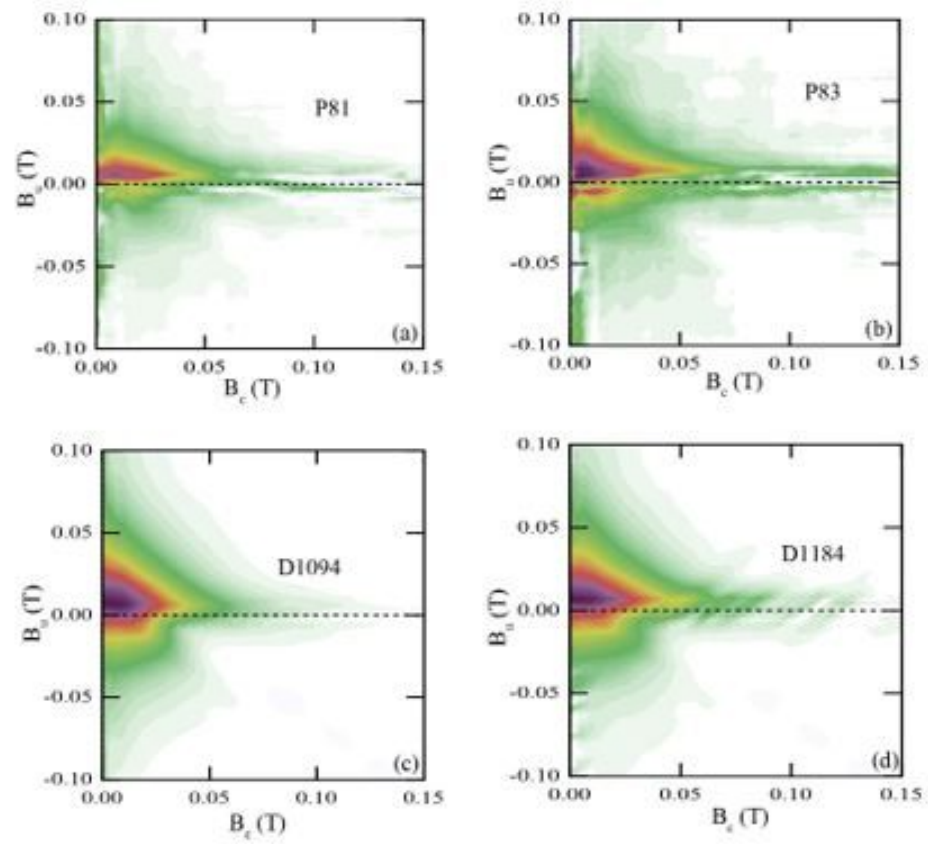

Figure 4

Examples of FORC diagrams measured on samples of topsoil (a-b) and roadside dust (c-d) with a smoothing factor of 4 